\title{
An investigation of accessible and inclusive instructional field practices in US geoscience departments
}

\author{
Ivan G. Carabajal ${ }^{1}$ and Christopher L. Atchison ${ }^{1,2}$ \\ ${ }^{1}$ College of Education, University of Cincinnati, Cincinnati, OH 45221, USA \\ ${ }^{2}$ Department of Geology, University of Cincinnati, Cincinnati, OH 45221, USA
}

Correspondence: Ivan G. Carabajal (carabaig@mail.uc.edu)

Received: 19 December 2019 - Revised: 16 April 2020 - Accepted: 1 May 2020 - Published: 11 June 2020

\begin{abstract}
This study examines current accessible field-based instructional strategies across geoscience departments in the United States that support students with visual, hearing, and mobility disabilities. A qualitative questionnaire was administered to geoscience instructors from over 160 US geology departments. Outcomes from the data analysis were used to categorize accessible instructional practices into three distinct pedagogical methods: modifications, accommodations, and options for accessible instructional design. Utilizing the lens of critical disability theory, we then investigated how the identified teaching practices varied in inclusion, as some strategies can often be more exclusionary towards individual students with disabilities. Although from a US perspective, the outcomes of this study offer practical suggestions for providing accessible and inclusive field experiences that may inform a global geoscience instructional context.
\end{abstract}

\section{Introduction}

According to the most recent World Report on Disability (WHO, 2011), $15 \%$ of the global population is living with a disability. In the United States, this translates to an underrepresentation of students with disabilities in STEM disciplines that is well documented (NSF, 2019). However, the total number of students marginalized from these programs remains largely unknown as disability data are only disclosed at the discretion of the student because US legislation such as the Family Educational Rights and Privacy Act (FERPA) and Health Insurance Portability and Accountability Act (HIPAA) protects the privacy of student's education and medical records, respectively. Additionally, surveys that seek de-identifiable data often do not distinguish between temporary and permanent conditions or specific types of disability and instead use varying definitions of disability when collecting personal information.

STEM disciplines related to the field-focused science disciplines (e.g., geology, ecology, anthropology) have the potential to inadvertently discourage students who are not drawn to activities that take place in the natural environment (Schwartz and Corkery, 2011; Sherman-Morris and McNeal, 2016), including those with disabilities (Carabajal et al., 2017; Hall et al., 2004; Healey et al., 2002). The prevalence of physically rigorous field practices (Hall and Healey, 2005) and the common assumptions, stereotypes, and biases held by practicing geoscientists of what those with disabilities can and cannot do (Atchison and Libarkin, 2016) give the impression that physical ability is a prerequisite to be a geoscientist (Locke, 2005). Investigations have reported that students with disabilities are often dissuaded from pursuing an interest in the geosciences because of the assumption that all geoscientists have to be field practitioners, causing students to self-assess their abilities and conclude that they may not be able to manage the rigorous program expectations and requirements to study in the field (Hall et al., 2004; Healey et al., 2002; Locke, 2005). In addition to these physical requirements, many geoscience educators identify the lack of flexible, accessibly designed learning opportunities that extend beyond the field as catalyzing the underrepresentation of students in career pathways and geoscientists with disabilities in the workforce (Atchison and Libarkin, 2016; Locke, 2005; NSF, 2019).

Attempting to address the underrepresentation of students with disabilities working towards geoscience careers, researchers have explored barriers that affect the participation of those with physical, sensory, and developmental dis- 
abilities in geoscience contexts (Bennett and Lamb, 2016; Carabajal et al., 2017; GSA, 2016; Hall et al., 2004; Hall and Healey, 2005; Locke, 2005), specifically focusing on the exclusionary culture within the discipline (Atchison et al., 2019; Beane et al., 2019; Mattheis et al., 2019). Guidelines for creating accessible and inclusive field-based experiences for students with mobility (Gardiner and Anwar, 2001), visual (Shepherd, 2001), and hearing disabilities (Wareham et al., 2006) have been presented in the geoscience education literature. However, the extent to which geoscience faculty make use of these resources to enable the participation of all learners within their courses is relatively unknown. Other sources that inform accessible teaching practice are in the form of instructional vignettes that have been shared to demonstrate how instructors have taught students with various disabilities in the field (Asher, 2001; Cooke et al., 1997; Wild et al., 2013). These sources provide a starting point for the geoscience education community to create both accessible and inclusive coursework.

While accessible and inclusive teaching practices both work to dismantle barriers that foster the social, physical, and cognitive abilities of one student over another, they are not the same. For the purposes of this study, accessible teaching practices refer to those in which all students, regardless of any disability, are able to participate. This may be physical access to a field site, having textbooks and laboratory manuals available in braille or audio format, or live captioning during lectures and discussions. Inclusive teaching practices, however, not only enable access to the content, but focus on the sociocultural engagement within the learning community by creating an equitable learning environment in which all students can collaborate and construct shared meanings from their unique and diverse perspectives.

This paper highlights an investigation into common instructional practices that actively support the participation of students with disabilities across US geoscience departments and provides evidence of strategies geoscience instructors have used to include students with mobility (e.g., cerebral palsy, arthritis), visual (e.g., blindness, color blindness), and hearing (e.g., Deaf or hard of hearing) disabilities in field experiences. Promoting various efforts made by instructors to support students with disabilities may encourage others to consider the impact of their own practice. Similarly, evaluating common instructional strategies for accessible and inclusive field-focused teaching may facilitate awareness of inclusive instructional effectiveness within the greater geoscience community that will broaden participation along the pathways to the geoscience workforce.

\section{Methods}

The aim of this study was to investigate instructors' practical experiences in support of students with physical and sensory disabilities in geoscience field courses. For the purposes of this work, "geoscience" is broadly defined as a science that attempts to understand natural Earth processes. The research process was guided by critical disability theory (CDT), a theoretical framework that aims to dismantle and denaturalize the concept of ableism by implementing a variety of diverse and intersectional lenses to analyze disability through cultural, historical, and social contexts and how those contexts relate to the powerlessness individuals with disabilities have within society (Meekosha and Shuttleworth, 2009; Pothier and Devlin, 2006). CDT posits that disability is a social construct created by the able-normative, or non-disabled, majority, who have designed social and physical aspects of the world according to their needs and abilities while failing to consider the same for people with disabilities (Pothier and Devlin, 2006). Through CDT, researchers are encouraged to challenge ideologies that label people as disabled and to promote social justice for individuals who are marginalized by the this social construct (Schalk, 2017). In the context of this study, and the discussion herein, CDT is used to critically analyze existing field-focused teaching strategies that fail to provide equitable learning opportunities for students with disabilities.

\subsection{Participants and setting}

An initial convenience sample of 60 volunteers was recruited at a major US geoscience conference, followed by an email solicitation to geoscience department representatives from over 800 US institutions. Participants consisted of a broad representation of geoscience instructors from department chairs, tenured and emeritus faculty, and field program directors to non-tenure track lecturers and graduate teaching assistants. Participants represented a variety of geoscience disciplines including geology, geophysics, atmospheric science, oceanography, mining or economic geology, soil science, environmental science, and space or planetary science from a variety of institutions throughout the US.

The geoscience accessibility questionnaire asked respondents to self-report demographic data. This included the role of the respondent (e.g., professor, associate professor, lecturer) and the types of degrees offered by their department, from associates degrees offered by 2-year community or technical college degree programs, similar to a foundational degree in the UK, up to doctoral degrees offered by postbaccalaureate programs. The degrees offered were used to assign each institution to one of four groups adapted from the Carnegie Classification of Institutions of Higher Education (Carnegie Commission on Higher Education, 2001). These categories included associate's or technical or community colleges (or 2-year colleges), baccalaureate colleges, master's colleges or universities, and doctoral universities. Of the 161 total responses, $90 \%(n=145)$ provided their department type. Seventeen percent of these respondents represented associate's colleges $(n=28), 27 \%$ represented baccalaureate colleges $(n=43), 12 \%$ were from master's col- 
leges or universities $(n=19)$, and $34 \%$ were from doctoral universities $(n=55)$, while $10 \%(n=16)$ did not provide information to determine their department type.

Respondents were also asked to share the number of students or faculty with disabilities in their respective department. Given that disability data are protected and a majority of disabilities are non-apparent, it is reasonable to assume that the data received may not reflect the total number of students or faculty with a disability in any given department population. However, given these constraints, geoscience departments at associate's colleges reported a higher population of students with disabilities (Table 1), consistent with current data suggesting that students with disabilities are more likely to attend a 2-year college (NSF, 2019).

\subsection{Data collection}

In order to understand inclusive and accessible teaching practices of post-secondary geoscience department instructors, an open-ended qualitative questionnaire was designed to capture rich descriptions of unique strategies to engage students with disabilities in field activities (Table 2). These experiences are often contextually dependent, and a qualitative approach provided instructors with an opportunity to describe the nature of their efforts to promote accessible and inclusive instruction. Additionally, the questionnaire collected departmental program demographics and the types and durations of field courses offered.

\subsection{Data analysis}

Qualitative studies employ iterative data analysis techniques to make meaning of descriptive data through coding. The coding process produces codes and sub-codes that are often reviewed and refined so that they express the essence of what is being investigated (Saldaña, 2016). The constant comparative method, a data analysis method used in grounded theory research, compares written responses to determine similarities and differences among the entire dataset, allowing for codes to be organized into categories that represent themes from the data (Glaser and Strauss, 1967). One benefit of using constant comparative analysis is that the method is considered highly rigorous among the qualitative research community and allows for other researchers to replicate the analytical process (Creswell and Poth, 2018; Merriam, 2009).

The data analysis process for this study was conducted in three stages: microanalysis, open coding, and axial coding to generate a list of themes that accurately identify and describe the kinds of practices geoscience departments use to provide students with disabilities with accessible fieldbased learning opportunities. During microanalysis, the entire dataset was read line by line to familiarize the coder with the survey responses. Any patterns that emerged during microanalysis were then noted, such as whether or not the instructional strategy required a student with a disability to participate in an activity different from their classmates. Survey data were then prepared for open and axial coding. Open coding is defined as an "analytical process through which concepts are identified and their properties and dimensions are discovered in data" (Strauss and Corbin, 1998, p. 101), and axial coding involves linking codes into broader themes while establishing the relationships between identified concepts. During open coding, practices identified from written responses were organized into 11 distinct instructional strategies. During axial coding, these strategies were then grouped into three pedagogical methods: modifications, accommodations, and accessible instructional design. Trustworthiness of the data analysis was established through interrater reliability, where an outside researcher experienced in qualitative inquiry independently coded the entire dataset using a schema established by the initial researcher. The separately coded data were compared between researchers leading to an $89 \%$ interrater agreement.

\section{Results and discussion}

This study revealed that instructional practice varied greatly among geoscience departments, including a variety of methods and strategies intended to promote accessibility in their instruction. Exploring different teaching practices through the lens of CDT, it is difficult to discern whether these practices either encourage the participation of students with disabilities or promote their exclusion from the discipline. For example, data indicated that ableism was perpetuated within some department cultures. One department chair (P132) described fieldwork as "not suitable for students that are mobility-impaired or sight-impaired" and made it known that this viewpoint is shared with all incoming geoscience students. Another participant described that offering accessible learning experiences were unnecessary, saying that “... we believe that changing the class to accommodate these disabilities goes beyond what is necessary under the Americans with Disabilities Act" (P108). While only these two respondents expressed ableist ideas, the majority were primarily concerned with supporting all students in geoscience field experiences, even if instructors were not familiar with approaching fieldwork from an accessible or inclusive perspective.

Data indicated three distinct pedagogical methods of providing accessible field-based experiences for students with disabilities: modifications, accommodations, and accessible instructional design. These pedagogical categorizations describe the extent to which students with disabilities were included in collaborative field activities with their peers, presented equitable geoscience content, or were supported by departmental policies designed to provide universal accessibility for all students. Overall, each of these major categories consisted of several specific teaching practices, each of which had unique implications for encouraging and sup- 
Table 1. Number of departments who report having one or more students or faculty members with a physical or sensory disability.

\begin{tabular}{lrrrr}
\hline Institution type & Total $N$ & Mobility disability & Hearing disability & Visual disability \\
\hline Associate & $N=28$ & $n=13(46.4 \%)$ & $n=4(14.3 \%)$ & $n=5(17.9 \%)$ \\
Baccalaureate & $N=43$ & $n=3(7.0 \%)$ & $n=6(14.0 \%)$ & $n=1(2.3 \%)$ \\
Master & $N=19$ & $n=0(0.0 \%)$ & $n=0(0.0 \%)$ & $n=2(10.5 \%)$ \\
Doctoral & $N=55$ & $n=16(29.1 \%)$ & $n=10(18.2 \%)$ & $n=9(16.4 \%)$ \\
\hline
\end{tabular}

Table 2. Portion of the survey distributed to participants.

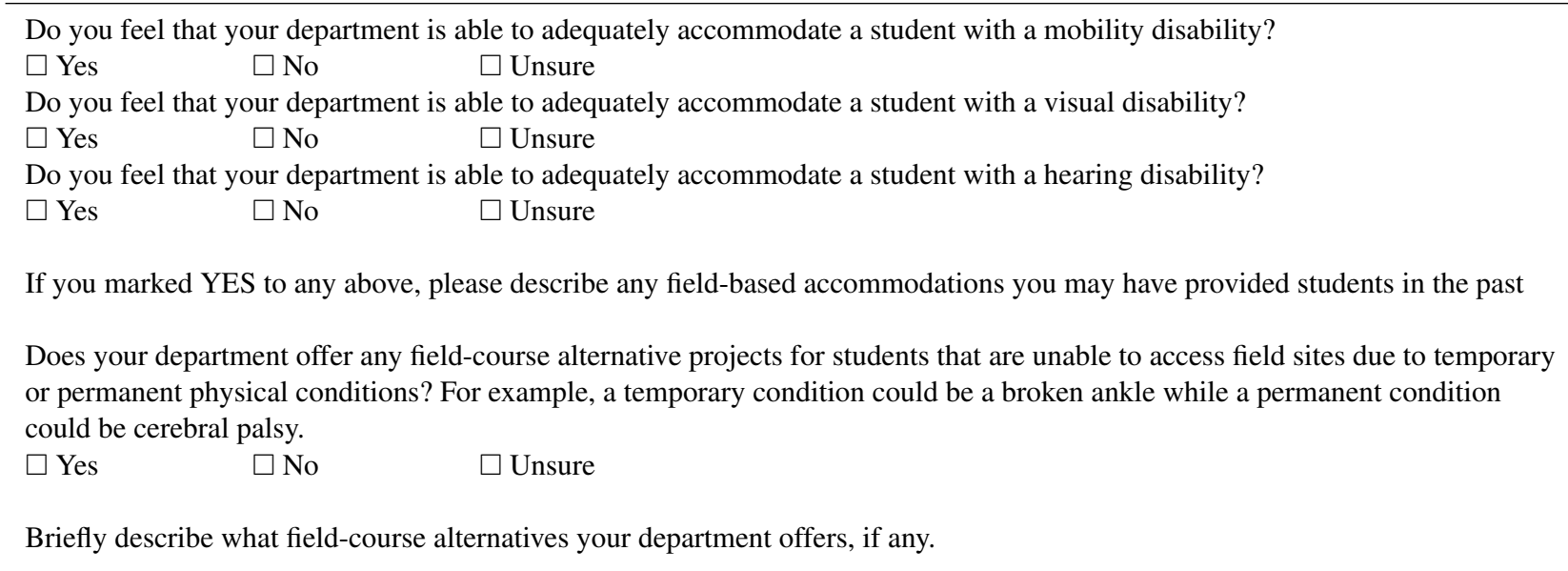

porting inclusion. However, some strategies did not adequately work to fully integrate students with disabilities into an accessible or inclusive community of learning as described by Atchison et al. (2019). In the following sections, we provide data to illustrate the three pedagogical methods in context as they relate to the degree of inclusive geoscience teaching and learning.

\subsection{Modifications}

The Individuals with Disabilities Education Act (IDEA) does not formally define accommodations or modifications at the US federal level, which can be troublesome as these terms may have alternate definitions depending on their use within the scientific community. Adapted from McLaughlin (2012), modifications are considered practices, devices, or interventions that allow a student with a disability access to instruction, although the core content and learning environments are changed and performance expectations are revised. Modifications within the context of field learning in this study are defined as an alternative method of instruction, instructional resource, or learning environment that enables a student with a disability to complete general course activities. However, a modified activity is often implemented to support the needs of a student with a disability, resulting in evaluation that differs from non-disabled peers. Four distinct teaching practices were identified and are provided in Table 3.

\subsubsection{Virtual learning experiences}

Instructors implement a variety of virtual learning experiences as a way of eliminating barriers to participation for students with mobility, hearing, and visual disabilities (Carabajal et al., 2017). Data show that instructors often rely on software such as Google Earth ${ }^{\mathrm{TM}}$ and other forms of satellite imagery to give students the ability to make observations of the environment without being in the field. Instructional methods that were also deemed to be virtual field experiences included videos taken during field trips, the use of topographic and geologic maps, and more technological applications that expresses landform relief (e.g., stereoscopy, digital elevation map data). Although virtual field experiences are beneficial for removing barriers preventing many students from participating in actual field studies, they are commonly designed as static websites or single-user environments (Carabajal et al., 2017). Virtual field experiences do not necessarily guarantee students with disabilities the opportunity to interact with their peers. As such, replacing an actual field activity with virtual learning can be an isolating experience that lacks constructive engagement and the chance to debate with peers and instructors in real-time. 
Table 3. Modification strategies for geoscience field accessibility.

\begin{tabular}{ll}
\hline Strategy & Definition \\
\hline Virtual learning experience & $\begin{array}{l}\text { Technology is used to simulate a project that is comparable to an in-field assignment to be completed } \\
\text { by able-normative peers (e.g., Google Earth }\end{array}$ \\
\hline Alternative field locality & $\begin{array}{l}\text { A student with a disability attends a field experience with able-normative peers and completes assign- } \\
\text { ments based on field localities individually and separate from the entire class. A student may be left at } \\
\text { camp or at a vehicle while the rest of the group leaves to view an inaccessible field site or complete an } \\
\text { assignment from a different focus area. }\end{array}$ \\
\hline Alternative assignments & $\begin{array}{l}\text { A student with a disability is assigned different assignments that may or may not be related to objectives } \\
\text { of the field experience in lieu of completing a field course. These alternative assignments may include } \\
\text { a research paper, additional laboratory assignments, or assignments based on previously collected field } \\
\text { data. }\end{array}$ \\
\hline Alternative field trips & $\begin{array}{l}\text { A student with a disability attends a field trip separate from their able-normative peers at a more acces- } \\
\text { sible location, often self-guided (e.g., a museum, campus building tour, or accessible park). }\end{array}$ \\
\hline
\end{tabular}

\subsubsection{Alternative field localities}

Students with mobility disabilities or other conditions that may impact their ability to access to a remote field site can be included in the field study by utilizing alternative field localities. This enables a student with a disability to attend a field trip with their peers, although the student may not be able to participate in every activity. Considering the degree of inclusion, alternative field localities allow students with disabilities to socially engage and collaborate with their peers, but they may be excluded during activities that occur at field locations that are physically inaccessible to them. Evidence for this practice was observed: "I don't require [students with disabilities] to go on all the hikes with the rest of the class. Usually we have another person who stays with them while the rest of the group is away" (P126) and "If we go to a place that is inaccessible, I have an alternative 'assignment' that they can do while waiting for the rest of us" (P107). Instructors depended on accessible localities such as road cuts, or less physically demanding routes around the major field area so that a student with a disability would still have the chance to participate in the learning community and complete fieldwork.

\subsubsection{Alternative assignments}

Out of all identified practices in this study, alternative assignments were determined to be the most implemented teaching practice in situations where students were physically unable to participate in a field trip. In several cases, alternative assignments are offered so that students with temporary disabilities (e.g., physical injury or illness) could receive credit without participating in a field experience or used to provide students with permanent disabilities with a way of completing program requirements towards certificates and degrees. These assignments are meant to replicate field concepts learned in the classroom, although they do not al- ways provide students with an authentic opportunity to apply these concepts in the natural environment. In one instance, a student received previously collected data to answer predetermined questions. "We don't have an alternative to an entire field course, but we have an alternate exercise wherein students who missed a trip would be required to analyze the structural data or use maps, photos, and figures to answer field questions" (P15). As this response indicates, alternative assignments are typically in the form of laboratory activities or research reports which a student can complete in lieu of missing the field-based activities of a course.

Nairn (1999) discusses the implications of missing out on collaborative learning and opportunities to apply classroom knowledge to field activities. A student's identity within the geosciences may be profoundly shaped by field study, therefore marginalizing those students who do not fit the ablebodied, field-rugged persona (Hall et al., 2004). By not participating in field activities, students are unable to develop the identity of a geoscience field practitioner (Nairn, 1999; Orion and Hofstein, 1994). The root of the issue here, as critical disability theorists would point out, is the alienation perpetuated by ableist ideas that field studies are only for those who are physically capable of performing such work. Rather than looking at exclusionary practices of field instruction, instructors should consider many of the resources presented in this paper as a starting point for designing field activities that support the abilities and experiences of every student.

\subsubsection{Alternative field trips}

Alternative field trips were identified in this study as a more accessible option for students with disabilities to complete required field course activities. Destinations for these trips can include doing a project in a publicly accessible park, museum, or some other location on or off campus. In most cases, alternative field trip activities occurred without the presence of an instructor; respondents reported that such trips 
were usually self-guided. In one survey response, an instructor noted that the student learning outcomes were insufficient and that it had "... not been very satisfactory" for the student (P128). One instructor "prepared a self-guided version of the physical geology field trip which students have taken later in the semester" (P131), in this case for a student who had a temporary injury that prevented their participation in the course field trip. Similarly, another instructor mentioned that a "student excused from Grand Canyon trip one year went the following year on his own initiative to make sure he had some experience" (P6). The extent to which each of these self-guided field trips supported student learning and overall understanding of the field content was not discussed. Another representative stated that allowing undergraduate students to complete independent fieldwork provided an incomplete learning experience and that "going to the field without a mentor is hard for a rookie" (P128). Mogk and Goodwin (2012) describe the importance of the student-mentor relationship in the field, which plays an important role in boosting student interest and motivation. The mentor also extends learning through probing for a deeper understanding by asking guiding questions and aligning thoughts with concrete examples. However, students who complete field activities individually may inadvertently fail to benefit from the construction of knowledge that comes from collaborative learning, which could place students at a disadvantage with respect to the academic outcomes of their course peers.

Aside from a lack of collaborative learning, alternative field experiences can often be detrimental to developing an interest and a sense of belonging in the discipline for students with disabilities. A field-based identity, as described above, is often developed in a socially constructed community of learning (Atchison et al., 2019; Nairn, 1999; Streule and Craig, 2016). Without a community to share observations and interpretations of geologic phenomena, students may fail to develop the collaborative skills needed to operate within a research team (Mogk and Goodwin, 2012) and negatively impact their sense of belonging to the community and the discipline.

\subsection{Accommodations}

Practices, devices, or interventions that enable a student with a disability to access the content, without diverging from course objectives or reducing student expectations, were identified as accommodations. For example, a braille textbook, an audio-recorded guidebook, or similar alternative representations of the same course materials being used in a course are accommodations for a student with a visual disability. Accommodations are aligned to the individual needs of the student and should be considered to support their full inclusion and participation in the learning community. Four specific accommodation practices were identified in this study and are detailed in Table 4.

\subsubsection{Department- or instructor-provided resources and assistance}

Situations where the department or an instructor provides personalized assistance so that a student with a disability is able to participate in a field learning activity with their peers are described as department- or instructor-provided resources or assistance. This may include driving students directly onto outcrops or a nearby overlook so students could view the field site. Providing students with multiple representations of the field content, including the use of hand samples and thin sections of the area rock types, aerial photographs, and Gigapan ${ }^{\mathrm{TM}}$ images would enable the student to make their own observations and interpretations of the environment (Atchison and Gilley, 2015; Houghton and Gordon, 2019; Houghton et al., 2020). To accommodate a student with a mobility disability, respondent P63 stated "we were able to pull his accessible van up very close to the outcrops and give him images and samples of the materials the students were examining". In cases of students with visual disabilities, assistance may include providing the student with a personal guide to accompany them during the trip or provide the student with accessible course materials (e.g., braille guidebooks, audio-recorded field notes, tactile models). One respondent (P91) used "3D plastic maps in lieu of topographic maps to help the student understand relief, landforms". For Deaf students or those who are hard of hearing, instructors may share field content through one-on-one discussions by communicating with students through an accessible medium (e.g., interpreters, speech to text technology, white board drawings; Hendricks et al., 2017). One geoscience instructor used "a portable large writing tablet (paper) into the field for written instruction" (P145).

Data revealed that, in some instances, instructors would completely redesign a field activity to include the participation of a student with a disability in the field with their peers. As reported by one instructor, a hiking route was selected with a particular student in mind "so that they don't feel singled out" (P107), thus providing an opportunity for the student to engage in the entire learning community. However, one instructor shared that modifying field activities for the sake of supporting the needs of a single student was not beneficial for the group, claiming that such practices "included disability student [sic] but slowed and decreased the experience for other students" (P6). Although this instructor did not describe how the experience negatively impacted the group, their response perpetuates the ableist perspectives presented earlier and highlights a lack of awareness of the benefits of having a diverse learning community and the need to properly train and mentor geoscience instructors in the effective design of inclusive and accessible field activities (Gardiner and Anwar, 2001). While ensuring all students are included in field trips may present logistical challenges, field experiences that are designed to engage the knowledge, abilities, and experiences of every student have the potential to 
Table 4. Accommodation strategies for geoscience field accessibility.

\begin{tabular}{ll}
\hline Strategy & Definition \\
\hline $\begin{array}{l}\text { Instructor- or department-provided } \\
\text { resources and assistance }\end{array}$ & $\begin{array}{l}\text { A student with a disability is provided with assistance so that they are able to participate in } \\
\text { field experience with their peers. Instructors may also completely redesign a field trip so that all } \\
\text { localities are accessible to enable a student with a disability to participate in the same activities } \\
\text { as their peers. }\end{array}$ \\
\hline $\begin{array}{ll}\text { Resources and assistance provided } \\
\text { by the university or office of dis- } \\
\text { ability services }\end{array}$ & $\begin{array}{l}\text { An instructor relies on or uses an on-campus office of disabilities services to accommodate a } \\
\text { student with a disability with resources or other methods of assistance (e.g., computer software, } \\
\text { sign language interpreter, field assistant) so that the student is able to participate in a field course. }\end{array}$ \\
\hline $\begin{array}{l}\text { Peer-provided assistance } \\
\text { Students with disabilities are paired with able-normative peers to provide in-field assistance. } \\
\text { Typically, an able-normative peer would be responsible for completing tasks such as data col- } \\
\text { lection at an inaccessible field site. }\end{array}$ \\
$\begin{array}{ll}\text { A student-provided resources and with a disability is responsible for securing their own resources in order to participate } \\
\text { assistance }\end{array}$ & $\begin{array}{l}\text { in a field course (e.g., bringing a personal assistant, sign language interpreters, or using their } \\
\text { own accessible vehicle). }\end{array}$ \\
\hline
\end{tabular}

pedagogically strengthen a learning community by focusing on the diversity of thought and perspective (Atchison et al., 2019).

\subsubsection{Resources and assistance provided by the university or office of disability services}

Instances when an instructor requested guidance from their campus office of disability services (ODS) to provide accommodations for students in the field were labeled as resources and assistance provided by the university or office of disability services. Typically, this would involve acquiring an accessible van, hiring a sign language interpreter, or requesting that field trip guides and materials be translated to braille and tactile graphics. In one case, an instructor reported that they had hired a field companion through ODS tasked with "going to the outcrop to fetch rock samples" (P132) to support a student with a mobile disability. One instructor pointed to the use of an ODS-provided American Sign Language (ASL) interpreter, but described an additional barrier common in Earth science: "Students have access to ASL interpreters through Disability Services [who] have come on field trips in the past (though this has generally proven challenging because of the specialized vocabulary)" (P152). Often, discipline-specific vocabulary does not have standardized ASL signs and requires tedious finger-spelling to communicate the content (Cavender et al., 2010). Although several instructors relied on ODS to provide services for students with disabilities, many were dissatisfied with their ability to provide accommodations during field trips. Obtaining support for students with disabilities during field activities is often most challenging as ODS typically provide accommodations for students inside the classroom and not in a physically rigorous field setting. Accommodations that are effective in the classroom are often ineffective in the field, similar to the practitioner experiences described by Feig et al. (2019).

\subsubsection{Peer-provided assistance}

Some instructors shared how they have relied on students enrolled in a course to assist a peer with a disability in field activities. While mixed-ability grouping, when done properly, has been shown to strengthen inclusive learning communities by supporting interactions of diverse perspectives and observations in the field, (Anderson, 2000; Atchison et al., 2019; Pettigrew, 1998), most instructors suggested that peer assistance was more a factor of convenience than an pedagogical strategy. For example, one instructor called peer-provided assistance "an added bonus" because "one of the students in the class (different section) was taking sign language and was able to practice as she paired up with this student during one of the field trips" (P130). In another situation, an instructor "paired visually impaired students with sighted students and had them work as teams" (P161). To accommodate a student with a mobility disability, one instructor "had students in the geomorphology course who have limited mobility partner with students who can do the field portion of the project" (P32). Pairing or grouping of students in the field should not primarily be about access to the field site, but rather a way of collaboratively sharing diverse observations and perspectives of the environment as it relates to application of the content (Atchison et al., 2019; Stokes et al., 2019).

\subsubsection{Student-provided resources and assistance}

Questionnaire responses pointed to instances when students with disabilities had to self-advocate for resources or personal assistance to the college or university in order to participate in a field course or were required to provide their own. One instructor mentioned how a student, on her sec- 
ond attempt to pass the course, "found her own companion... and brought the woman she lived with" (P102) to complete a field course. Another department required students with disabilities to "drive their own vehicles separately or have a friend or relative drive them with the additional vehicle following the bus" (P131). Based on participant responses, students were responsible for contacting ODS to request the resources or personal assistance they needed to participate in a course-required field activity. Several respondents also mentioned that students who were Deaf or hard of hearing had to rely on lip reading when an ODS interpreter was not available for the field trip. Situations where a student with a disability has to advocate for their own inclusion in a field course while also focusing on their academic responsibilities undoubtedly increases their cognitive load and anxiety and may add an undue financial burden. Even students with temporary physical injuries or illnesses are affected as they may also be expected to independently complete field activities at a later date. To alleviate the burden of self-advocacy and self-accommodation, instructors should communicate directly with students to determine the best possible way to serve their needs while also focusing on the academic objectives of the course. Instructors who communicate early and often with students tend to develop a more trusting relationship where students feel valued and encouraged to share how to best support them in the field (Atchison and Gilley, 2015; Hendricks et al., 2017).

\subsection{Accessible instructional design}

Accessible instructional design is the practice of using universally designed teaching methods to include and engage all students in an activity or course regardless of the students' abilities (Rose and Meyer, 2002). Practices labeled as accessible instructional design had the key distinction of being implemented proactively; policies or field trips were built to eliminate barriers to participation enabling all students to engage in an inclusive community of learning (Atchison et al., 2019). The three distinct practices of accessible instructional design are detailed in Table 5.

\subsubsection{Multiple-degree track}

Geoscience departments that offer multiple degree options, with or without a focus on field instruction, were considered as providers of multiple-degree tracks. In these situations, all students, regardless of disability status, are able to pursue any degree pathway that is aligned to their interests and abilities. For example, some departments have less field requirements for students completing a BA degree when compared to their BS degree. As reported by one respondent, multipledegree tracks may lighten the physical exertion and anxiety related to traditional geoscience courses and adjust the academic focus: "one-degree track that does not include the field mapping course; it emphasizes education skills and climate change" (P30). Offering multiple degree options to every student may eliminate the social stigma associated with requesting accommodations or alternative coursework. Presenting students with pathways to geoscience careers that may not have field requirements could help improve diversity in the geoscience workforce and promote the participation of people with disabilities.

\subsubsection{Optional field trips}

Studies have shown that field experiences improve student learning (Garrison and Endlsey, 2005; Mogk and Goodwin, 2012; Whitmeyer et al., 2009), even though some geoscience departments permit students to opt out of field activities. Our research shows that some departments permitted all students, regardless of disability status, to opt out of field trips. One department representative reported that, although participation in field was "strongly recommended" (P110), field activities had no weight in their final course grades. No information was provided to determine how geoscience understanding was impacted by the lack of field trip participation. From the survey data, respondents who indicated students were permitted to opt out of field activities were only from 2-year colleges. Although optional field experiences provide flexibility for students with disabilities to complete coursework towards degree completion, students may miss the valuable opportunity to apply key geology classroom knowledge to infield situations. The completion of field experiences is often necessary for undergraduate and graduate degree completion in US geoscience departments, which may explain why only 2-year colleges reportedly offered optional field trips for students. Rather than eliminating the field experience, instructors should instead consider how to best support all students in field activities by minimizing the barriers preventing access and inclusion. Field inclusion and field accessibility are not synonymous. Full collaborative participation in an activity does not necessarily mean total access to every location in the field (Atchison et al., 2019).

\subsubsection{Universally accessible field design}

Several respondents indicated that their department offered accessible field courses that are designed to enable all students to navigate the field according to their own level of experience and ability. Other departments were aware of accessible field courses offered by other institutions and recommended students to attend those. The creation of a universally accessible field experience requires a host of logistical considerations. For example, one such consideration is the availability of accessible transportation. One respondent designed a field trip that utilized public transportation which is required to be accessible according to the Americans with Disabilities Act (ADA) and created course materials in multiple formats, stating that "the field guide is presented in text or audio file, or a screen reader can read it" (P127). Field 
Table 5. Accessible instructional design strategies for geoscience field accessibility.

\begin{tabular}{ll}
\hline Strategy & Definition \\
\hline Multiple-degree track & $\begin{array}{l}\text { A department offers multiple-degree tracks with and without mandatory field components. } \\
\text { These multiple-degree tracks are available to all students, regardless of disability status. }\end{array}$ \\
\hline Optional field trips & A department does not require the completion of field components for degree completion. \\
\hline Universally accessible field design & $\begin{array}{l}\text { Required field courses are designed to be accessible for all students or enable students to navi- } \\
\text { gate the field according to their level of ability. }\end{array}$ \\
\hline
\end{tabular}

trip stops were in publicly accessible locations, such as museums and parks. Respondent P145 reported that such a practice "restricts some activities but allows students the opportunity to conduct field work." This flexible design of field activities and using multiple instructional strategies to present field content can create an environment of inclusive learning, maintaining academic rigor while also reducing the stigma and anxiety associated with having a disability in an inaccessible field site.

\section{Conclusion}

This study offers insight into current practices of inclusion and accessibility in field-based teaching and learning within US geoscience departments. Although this study is based on practices within the US, we expect that most of the effective strategies described here will be widely applicable in other countries where students with disabilities have access to geoscience programs in post-graduate educational institutions. Designing field activities and courses that support the needs of all students can be difficult as there is no one-sizefits-all approach to accessibility and inclusion. Instructional strategies can vary according to the needs of the student, the learning goals of the field experience, and the accessibility of the field locality. In addition, an instructor's prior knowledge of accessible, pedagogical practices can shape the outcome of a field learning experience.

As geoscience instructors continue to modify current practice and create new curricula, understanding and prioritizing both access and inclusion are key to encouraging active engagement and participation across a range of student ability in all geoscience disciplines. One of the more common practices to engage students with disabilities is the use of alternative assignments. Alternative assignments are easy to implement as they require less planning when compared to redesigning a field course to be accessible, but alternative assignments perpetuate exclusion by marginalizing students with disabilities from the learning community for the sake of liability and convenience. Not providing students with access to group field activities is problematic as these activities isolate students from their peers and limit chances for students to develop their own identity as a geoscience practitioner. As much as those of us who work on diversity issues would like to think otherwise, the culture of the geosciences is inherently focused on fieldwork identity and not on the accessible opportunities that are available across the discipline. More geoscience departments may want to utilize purposeful site selection and the multiple representation of accessible course materials that allows more access to the field. If instructors continue to describe the field as the ideal place for geoscience learning, then we must be working diligently to include all students in these valuable learning experiences.

Data availability. The Institutional Review Board approval for this study does not allow for public access of survey respondents. Please direct any correspondence to the primary author (carabaig@mail.uc.edu).

Author contributions. IGC and CLA both designed the survey. IGC distributed the survey to geoscience departments and collected and then analyzed the data. IGC and CLA both contributed to the paper.

Competing interests. The authors declare that they have no conflict of interest.

Disclaimer. Any opinion, findings, and conclusions or recommendations expressed in this material are those of the authors and do not necessarily reflect the views of the National Science Foundation.

Special issue statement. This article is part of the special issue " $\mathrm{Di}$ versity and equality in the geosciences (EGU2019 EOS6.1 \& US4, AGU2018 ED41B, JpGU2019 U-02)". It is a result of the AGU Fall Meeting 2018, Washington, United States, 10-14 December 2018.

Acknowledgements. The authors would like to thank Julie Libarkin, Craig Dietsch, and Warren Huff for their support and assistance. Moreover, the authors are grateful to the editor, Jill Karsten, and Alison Stokes and an anonymous referee for their reviews of the manuscript. 
Financial support. This research has been supported by the Geological Society of America Graduate Student Research Grant Award (contract no. 11193-16), the University of Cincinnati Graduate Student Governance Association Diversity/Interdisciplinary Research Fellowship Award, and by the National Science Foundation Graduate Research Fellowship award (grant no. 1610397).

Review statement. This paper was edited by Jill Karsten and reviewed by Alison Stokes and one anonymous referee.

\section{References}

Anderson, N. B.: Guidelines on multicultural education, training, research, practice, and organizational change for psychologists, Am. Psychol., 58, 377-402, 2000.

Asher, P.: Teaching an introductory physical geology course to a student with visual impairment, J. Geosci. Educ., 49, 166-169, 2001.

Atchison, C. L. and Gilley, B.: Geology for everyone: Making the field accessible, Earth Mag., September, 24-33, 2015.

Atchison, C. L. and Libarkin, J. C.: Professionally held perceptions about the accessibility of the geosciences, Geosphere, 12, 11541165, https://doi.org/10.1130/GES01264.1, 2016.

Atchison, C. L., Marshall, A. M., and Collins, T. D.: A multiple case study of inclusive learning communities enabling active participation in geoscience field courses for students with physical disabilities, J. Geosci. Educ., 67, 472-486, https://doi.org/10.1080/10899995.2019.1600962, 2019.

Beane, R., McNeal, K. S., and Macdonald, R. H.: Probing the National Geoscience Faculty Survey for reported use of practices that support inclusive learning environments in undergraduate courses, J. Geosci. Educ., 67, 427-445, https://doi.org/10.1080/10899995.2019.1621714, 2019.

Bennett, R. A. and Lamb, D. A.: Accessibility and innovation, Nat. Geosci., 9, 263, https://doi.org/10.1038/ngeo2685, 2016.

Carabajal, I. G., Marshall, A. M., and Atchison, C. L.: A synthesis of instructional strategies in geoscience education literature that address barriers to inclusion for students with disabilities, J. Geosci. Educ., 65, 531-541, https://doi.org/10.5408/16-211.1, 2017.

Carnegie Commission on Higher Education: The Carnegie classification of institutions of higher education, 2000 Edn., Carnegie Publications, Menlo Park, CA, available at: http://carnegieclassifications.iu.edu/downloads/2000_edition_ data_printable.pdf (last access: 5 June 2020), 2001.

Cavender, A. C., Otero, D. S., Bigham, J. P., and Ladner, R. E.: ASL-STEM forum: Enabling sign language to grow through online collaboration, in: Proceedings of the SIGCHI Conference on Human Factors in Computing Systems, Association for Computing Machinery, New York, NY, 2010.

Cooke, M. L., Anderson, K. S., and Forrest, S. E.: Creating accessible introductory geology fieldtrips, J. Geosci. Educ., 45, 4-9, 1997.

Creswell, J. W. and Poth, C. N.: Qualitative inquiry and research design: Choosing among five approaches, 4th Edn., Sage, Thousand Oaks, CA, 2018.
Feig, A. D., Atchison, C. L., Stokes, A., and Gilley, B.: Achieving inclusive field-based education: Results and recommendations from an accessible geoscience field trip, J. Scholarsh. Teach. Learn., 19, 66-87, https://doi.org/10.14434/josotl.v19i1.23455, 2019.

Gardiner, V. and Anwar, N.: Providing Learning Support for Students with Mobility Impairments Undertaking Fieldwork and Related Activities, edited by: Gravestock, P. and Healey, M., Geography Discipline Network (GDN), Geography \& Environmental Management Research Unit (GEMRU), University of Gloucestershire, Cheltenham, Gloucestershire, UK, available at: https://gdn.glos.ac.uk/disabil/mobility/mobility.pdf (last access: 5 June 2020), 2001.

Garrison, J. R. J. and Endlsey, G.: Field-based geoscience education: A valid experience in outdoor education, Texas Sci. Teach., 34, 23-29, 2005.

Glaser, B. and Strauss, A.: The discovery of grounded theory: Strategies for qualitative research, Aldine, New York, NY, 1967.

GSA (Geological Society of America): Expanding and improving geoscience in higher education, available at: https://www. geosociety.org/gsa/positions/position18.aspx (last access: 1 January 2017), 2016.

Hall, T. and Healey, M.: Disabled students' experiences of fieldwork, Area, 37, 446-449, 2005.

Hall, T., Healey, M., and Harrison, M.: Fieldwork and disabled students: discourses of exclusion and inclusion, J. Geogr. High. Educ., 28, 255-280, https://doi.org/10.1080/0309826042000242495, 2004.

Healey, M., Roberts, C., Jenkins, A., and Leach, J.: Disabled Students and Fieldwork: Towards Inclusivity?, Planet, 6, 24-26, 2002.

Hendricks, J. E., Atchison, C. L., and Feig, A. D.: Effective use of personal assistants for students with disabilities: lessons learned from the 2014 Accessible Geoscience Field Trip, J. Geosci. Educ., 65, 72-80, https://doi.org/10.5408/16-185.1, 2017.

Houghton, J. J. and Gordon, C.: Access Anglesey: An inclusive and accessible field class, Teach. Earth Sci., 44, 7-11, 2019.

Houghton, J. J., Morgan, D. J., Gordon, C., Stokes, A., Atchison, C. L., Collins, T. D., Craven, B., and Willis, K.: Access Anglesey 2018: Lessons from an inclusive field class, Adv. Geosci., in press, 2020.

Locke, S. M.: The status of persons with disabilities in the geosciences, White Paper, New Mexico State University, Las Cruces, NM, 2005.

Mattheis, A., Murphy, M., and Marin-Spiotta, E.: Examining intersectionality and inclusivity in geosciences education research: A synthesis of the literature 2008-2018, J. Geosci. Educ., 67, 1-13, https://doi.org/10.1080/10899995.2019.1656522, 2019.

McLaughlin, M. J.: Access for all: Six principles for principals to consider in implementing CCSS for students with disabilities, Principal, September/October, 22-26, available at: https://www. naesp.org/sites/default/files/McLaughlin_2012.pdf (last access: 5 June 2020), 2012.

Meekosha, H. and Shuttleworth, R.: What's so "critical" about critical disability studies?, Aust. J. Hum. Rights, 15, 47-76, 2009.

Merriam, S. B.: Qualitative research: A guide to design and implementation, 2nd Edn., Jossey-Bass, San Francisco, CA, 2009.

Mogk, D. W. and Goodwin, C.: Learning in the field: Synthesis of research on thinking and learning in the geosciences, in: Earth 
and Mind II: A Synthesis of Research on Thinking and Learning in the Geosciences: Geological Society of America Special Paper 486, edited by: Kastens, K. A. and Manduca, C. A., 131-163, Geological Society of America, Boulder, CO, 2012.

Nairn, K.: Embodied fieldwork, J. Geogr., 98, 272-282, https://doi.org/10.1080/00221349908978941, 1999.

NSF (National Science Foundation and National Center for Science and Engineering Statistics): Women, minorities, and persons with disabilities in science and engineering: 2019, Alexandria, VA, 2019.

Orion, N. and Hofstein, A.: Factors that influence learning during a scientific field trip in a natural environment, J. Res. Sci. Teach., 31, 1097-1119, https://doi.org/10.1002/tea.3660311005, 1994.

Pettigrew, T. F.: Intergroup contact theory, Annu. Rev. Psychol., 49, 65-85, 1998.

Pothier, D. and Devlin, R.: Toward a critical theory of discitizenship, in: Critical disability theory: essays in philosophy, politics, policy, and law, edited by: Pothier, D. and Devlin, R., UBC Press, Vancouver, BC, 2006.

Rose, D. H. and Meyer, A.: Teaching every student in the digital age: Universal design for learning, ASCD, Alexandria, VA, 2002.

Saldaña, J.: The coding manual for qualitative researchers, 3rd Edn., Sage, Thousand Oaks, CA, 2016.

Schalk, S.: Critical disability studies as methodology, Lateral, 6, 1, https://doi.org/10.25158/L6.1.13, 2017.

Schwartz, A. and Corkery, M. R.: Barriers to Participation among Underrepresented Populations in Outdoor Programs, Recreat. Sport. J., 35, 130-144, https://doi.org/10.1123/rsj.35.2.130, 2011.

Shepherd, I.: Providing Learning Support for Blind and Visually Impaired Students Undertaking Fieldwork and Related Activities, edited by: Gravestock, P. and Healey, M., Geography Discipline Network (GDN), Geography \& Environmental Management Research Unit (GEMRU), University of Gloucestershire, Cheltenham, Gloucestershire, UK, available at: https://gdn.glos. ac.uk/disabil/blind/blind.pdf (last access: 5 June 2020), 2001.
Sherman-Morris, K. and McNeal, K. S.: Understanding Perceptions of the Geosciences Among Minority and Nonminority Undergraduate Students, J. Geosci. Educ., 64, 147-156, https://doi.org/10.5408/15-112.1, 2016.

Stokes, A., Feig, A. D., Atchison, C. L., and Gilley, B.: Making geoscience fieldwork inclusive and accessible for students with disabilities, Geosphere, 15, 1809-1825, https://doi.org/10.1130/GES02006.1, 2019.

Strauss, A. and Corbin, J.: Basics of qualitative research: Techniques and procedures for developing grounded theory, Sage, Thousand Oaks, CA, 1998.

Streule, M. J. and Craig, L. E.: Social learning theories-an important design consideration for geoscience fieldwork, J. Geosci. Educ., 64, 101-107, https://doi.org/10.5408/15-119.1, 2016.

Wareham, T., Clark, G., and Turner, R.: Developing an inclusive curriculum for students with hearing impairments, edited by: Hills, M. and Healey, M., Geography Discipline Network (GDN), University of Gloucestershire, Cheltenham, Gloucestershire, UK, available at: https://gdn.glos.ac.uk/disabil/deaf/deaf. pdf (last access: 5 June 2020), 2006.

WHO (World Health Organization): World report on disability, Geneva, CH, 2011.

Whitmeyer, S. J., Mogk, D. W., and Pyle, E. J.: An introduction to historical perspectives on and modern approaches to field education, Geol. Soc. Am. Spec. Pap., 461, vii-ix, https://doi.org/10.1130/2009.2461(00), 2009.

Wild, T. A., Hilson, M. P., and Farrand, K. M.: Conceptual Understanding of Geological Concepts by Students With Visual Impairements, J. Geosci. Educ., 61, 222-230, https://doi.org/10.5408/12-379.1, 2013. 